\title{
Climate change impacts on the hydrologic regime of a Canadian river: comparing uncertainties arising from climate natural variability and lumped hydrological model structures
}

\author{
G. Seiller and F. Anctil \\ Chaire de recherche EDS en prévisions et actions hydrologiques, Université Laval, \\ Département de génie civil et de génie des eaux, 1065, avenue de la Médecine, Québec, Qc, G1V0A6, Canada
}

Correspondence to: G. Seiller (gregory.seiller.1@ulaval.ca)

Received: 31 October 2013 - Published in Hydrol. Earth Syst. Sci. Discuss.: 19 November 2013

Revised: 11 April 2014 - Accepted: 17 April 2014 - Published: 3 June 2014

\begin{abstract}
Diagnosing the impacts of climate change on water resources is a difficult task pertaining to the uncertainties arising from the different modelling steps. Lumped hydrological model structures contribute to this uncertainty as well as the natural climate variability, illustrated by several members from the same Global Circulation Model. In this paper, the hydroclimatic modelling chain consists of twenty-four potential evapotranspiration formulations, twenty lumped conceptual hydrological models, and seven snowmelt modules. These structures are applied on a natural Canadian subcatchment to address related uncertainties and compare them to the natural internal variability of simulated climate system as depicted by five climatic members. Uncertainty in simulated streamflow under current and projected climates is assessed. They rely on interannual hydrographs and hydrological indicators analysis. Results show that natural climate variability is the major source of uncertainty, followed by potential evapotranspiration formulations and hydrological models. The selected snowmelt modules, however, do not contribute much to the uncertainty. The analysis also illustrates that the streamflow simulation over the current climate period is already conditioned by the tools' selection. This uncertainty is propagated to reference simulations and future projections, amplified by climatic members. These findings demonstrate the importance of opting for several climatic members to encompass the important uncertainty related to the climate natural variability, but also of selecting multiple modelling tools to provide a trustworthy diagnosis of the impacts of climate change on water resources.
\end{abstract}

\section{Introduction}

The modelling of climate change impacts on water resources remains a major challenge encompassing numerous uncertainties, from the definition of a greenhouse gas scenario to the calculation of the hydrological projection. Every modelling tool involved in this process can potentially affect our ability to render a precise diagnosis of the future.

Quantifying the uncertainties associated with the modelling of climate change impacts asks for a consistent and documented approach, reflecting the state of the scientific knowledge (Kiparsky and Gleick, 2004; Dettinger, 2005; Maurer, 2007). These uncertainties may be separated into two components: "incomplete" knowledge, reflected by model conceptualization, and "unknowable" knowledge, related to human and climate system behaviours (Carter et al., 1999). Among the four levels of climate-change-impactmodelling uncertainties (Boé et al., 2009), three are associated with future climate calculations (gas emissions scenarios, global climate modelling, and downscaling) and one, to hydrological modelling. Several studies addressed all of them (e.g. Vicuna et al., 2007; Minville et al., 2008; Kay et al., 2009; Boyer et al., 2010; Görgen et al., 2010; Teng et al., 2012; Jung et al., 2012) while others focused on specific ones (e.g. Ludwig et al., 2009; Gardner, 2009; Poulin et al., 2011; Bae et al., 2011; Teng et al., 2012; Velázquez et al., 2013). However, all these works are based on ensemble intercomparison and advocate the necessity of assessing uncertainties before, for example, comparing river discharges over reference (REF) and future (FUT) periods. 
For instance, Minville et al. (2008) found that global climate models (GCMs) initiate an important part of the uncertainty but so does, to a lesser extent, climate downscaling and hydrological modelling. Kay et al. (2009) arrived to similar conclusions. They compared six different sources of uncertainty: gas-emission scenarization, GCM, climate downscaling, natural variability (which is disclosed calculating GCM runs from slightly modified initial conditions), and hydrological model structures and parameters. They found that all contribute to the total uncertainty and that GCMs are the most uncertain. For their part, Teng et al. (2012) exploited fifteen GCMs and operated five hydrological model structures to show that the uncertainty deriving from the hydrological modelling should not be disregarded. Conclusions shared by Prudhomme et al. (2003), Vicuna et al. (2007), Boé et al. (2009), Quintana Seguí et al. (2010), and others.

Hydrologists continue improving their models, yet the role of the model structures in climate change impacts studies is still little known. Intercomparison studies offer a simple way of unravelling uncertainties associated with the many hydrological structures and concepts. As an example, Ludwig et al. (2009) focused on uncertainties emanating from hydrological modelling, comparing structures of different complexity. They confirmed the importance of the climatic projection uncertainty (i.e. scenarios, GCM, downscaling) but also stressed that hydrological modelling tools must be carefully evaluated and that a coherent protocol must be developed. Poulin et al. (2011) identified equifinal parameter sets for two hydrological structures implemented on a Canadian catchment. They concluded that model structures and parameter identification are important sources of uncertainty under a changing climate. Velázquez et al. (2013) confirmed that the selection of a hydrological model affects climate change impacts conclusions, especially for low flows on two dissimilar catchments, in Germany and Canada.

Many hydrological models resort to a simplistic approach to simulate the actual evapotranspiration, namely to an agronomic concept called potential evapotranspiration (PET), representative of constant crop and soil conditions. PET formulations are largely influenced by a changing climate (changes in the evaporative demand) and are thus a supplemental source of uncertainty. However, scant research addresses this question even if the diversity of PET formulations and concepts is compatible for intercomparison. As an example, Kay and Davies (2008) found that the Penman equation, compared to a simple temperature-based formulation (Oudin et al., 2005) in a climate change context with A2 scenario, offers very different results for climate-changeimpact modelling on water resources for the 2071-2100 period. They advised that the choice of a PET formulation affects hydrological projections. Bae et al. (2011) evaluated uncertainties from hydrological models and PET formulations on a Korean catchment. They compared three hydrological models, three PET formulations, and thirty-nine climate scenarios for the 2020 and 2080 horizons. Their results showed that hydrological modelling affects total uncertainty, revealing the importance of the PET formulation and demonstrating the need to account for them in climate change impacts assessment projects. In addition, Bormann (2011) compared eighteen PET computations over six German meteorological stations and found a large sensitivity to climate.

The authors are aware of no work addressing the hydrological projections uncertainty emanating from lumped snow modules, but the literature targeting snowmelt modelling (e.g. WMO, 1986; Valéry, 2010; Franz et al., 2010) reported large uncertainties on the simulated discharge. It is thus expected that this variability remains at least as important under changing climate.

In this work, PET formulations, snow modules, and lumped hydrological structures are compared, along with the natural variability of the simulated climate system. This later concept is illustrated here with a climatic ensemble based on five members with slightly different initial conditions, such as in Deser et al. (2012), where the natural climate variability refers to the "unforced variability internal to the real or simulated climate system" as evaluated with 40 members. Climate simulation ensembles allow the analysis of their internal variability (which is mainly a demonstration of natural variability) and can be seen as the irreducible fraction of climate simulations uncertainty (Kay et al., 2009; Velázquez et al., 2013), a part of the "unknowable" knowledge stated above. Climatic reference simulations (REF) and future projections (FUT) may then vary substantially from one member of the ensemble to the other. Indeed, the chaotic nature of the climate produces dissimilar time series when a GCM is initiated with slightly modified conditions, here in 1850 . The natural climate uncertainty, described by equally valid climatic members ( $\mathrm{C} 1$ to $\mathrm{C} 5$ ), will thus serve as benchmark for the other explored sources of uncertainty.

More specifically, this project compares uncertainties related to the natural climate variability and to lumped hydrological model structures, in the context of climate change impacts on the hydrologic regime of a Canadian river. It will illustrate what is our ability to produce a diagnosis of climate change impacts on the water resources of the au Saumon catchment.

\section{Material and methods}

\subsection{The au Saumon catchment}

The Haut-Saint-François catchment drains a $2940 \mathrm{~km}^{2}$ territory located $120 \mathrm{~km}$ south of Quebec City and $200 \mathrm{~km}$ east of Montreal. It fosters three dams for flood control, environmental needs, recreational activities, and water consumption - the lower one is mostly dedicated to hydroelectric production. The natural au Saumon (SAU) sub-catchment, upstream the Haut-Saint-François River, receives waters from a $738 \mathrm{~km}^{2}$ area along a south-southeast to north-northwest 


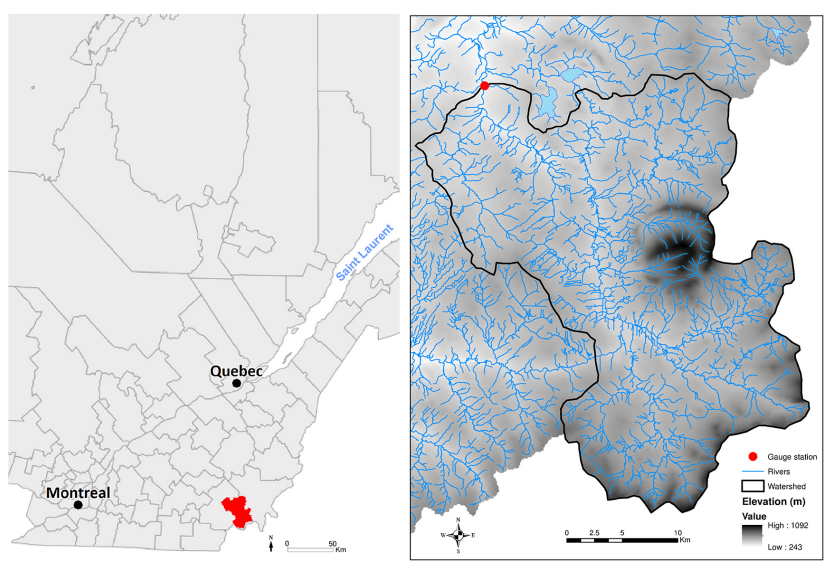

Figure 1. Localisation of the au Saumon catchment $\left(738 \mathrm{~km}^{2}\right.$; Canada).

path. Figure 1 details this location and its geographic characteristics. The hydrographic network is dense and uniformly distributed, altitudes range from 277 and $1092 \mathrm{~m}$, land use is dominated by mixed coniferous/deciduous forests and agricultural lands, while the geology is dominated by limestone, sandstone, and shale. The hydrologic regime is characterized by an important spring freshet (from March to May) and high autumnal flows.

\subsection{Hydrological, meteorological and climatic data}

Hydrological and meteorological data are provided by the Centre d'expertise hydrique du Québec. Hydrometrical data correspond to daily discharges from the au Saumon gauging station (1975 to 2003). The annual mean discharge reaches $771 \mathrm{~mm}$ (approximately $18 \mathrm{~m}^{3} \mathrm{~s}^{-1}$ on an average day).

Meteorological observations consist in daily mean, minimum and maximum air temperatures $\left({ }^{\circ} \mathrm{C}\right)$, daily total precipitation $(\mathrm{mm})$, incoming solar radiation $\left(\mathrm{W} \mathrm{m}^{-2}\right)$, relative

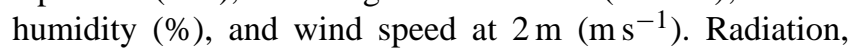
humidity and wind speed measurements originate from the nearby Sherbrooke station, outside of the watershed. All data are spatially lumped over the catchment and extend from 1975 to 2003 . Mean temperature attains $4.5^{\circ} \mathrm{C}$ but only $-11^{\circ} \mathrm{C}$ in January. Precipitation is quite uniform over the year and averages $1284 \mathrm{~mm}$, with $355 \mathrm{~mm}$ as solid precipitation. Maximal incoming solar radiation occurs in June $\left(246 \mathrm{~W} \mathrm{~m}^{-2}\right)$, while the relative daily humidity fluctuates between $73 \%$ (April) and $85 \%$ (September). Average wind oscillates from $2 \mathrm{~m} \mathrm{~s}^{-1}$ (August) to $3.5 \mathrm{~m} \mathrm{~s}^{-1}$ (March).

Climatic data originated from the Canadian Global Climate Model (CGCM version 3 with a $3.75^{\circ}$ resolution, Scinocca et al., 2008), fed with SRES (Special Report on Emissions Scenarios) A2 scenario (Nakicenovic et al., 2000). Data were dynamically downscaled by the Canadian Regional Climate Model (CRCM version 4.2.3, de Elía and Côté, 2010). The CRCM domain consisted of $111 \times 87$ grid points with a $45 \mathrm{~km}$ resolution (true at $60^{\circ} \mathrm{N}$ ) centered on the Province of Quebec.

Downscaled climatic data were provided by Consortium Ouranos: reference simulations (REF) cover 1971 to 2000 while future projections (FUT), 2041 to 2070 (2050s horizon). The climate natural variability is depicted by five climatic members ( $\mathrm{C} 1$ to $\mathrm{C} 5)$ that were bias-corrected to reduce deviation between REF and observations on precipitation and temperature. Monthly correction factors were computed for each climatic member on the 30-year monthly average minimum and maximum temperatures and were applied on each member to preserve their respective variance. Precipitation was corrected using the local intensity (LOCI) scaling method (Schmidli et al., 2006), adjusting mean monthly precipitation in terms of frequencies and intensity over 30 years. This procedure assumes that these corrections are maintained in future climate. Monthly average FUT temperature time series increase between 2 and $3^{\circ} \mathrm{C}$, without much variability between climatic members. Precipitation highlights a larger variability than temperature from one climatic member to the other. Projected precipitation changes are substantial, increasing mostly from October to May and decreasing in summer. Incoming solar radiation slightly increases on FUT from June to August and relative humidity is mostly unchanged, with a small increase in March. Wind speed slightly increases in FUT (maximum $+0.8 \mathrm{~m} \mathrm{~s}^{-1}$ ).

\subsection{Hydroclimatic modelling chain}

The main objective of this intercomparison consists in evaluating multiple representations of hydrological modelling behaviours, beyond the pre-supposed most appropriate model, because models are conceptualisations of real systems. It would then be possible to evaluate and quantify structural uncertainties in a climate change context. The issue is to select relevant hydrological modelling tools in terms of number, diversity and pertinence, since they must be hypothetically appropriate for simulating catchment flows and must be known for their performance.

\subsubsection{Twenty lumped conceptual hydrological models}

Researches led by Perrin et al. $(2001,2003)$ and by Mathevet (2005) provide a hefty source of information on lumped conceptual hydrological models. It concerns a large number of rainfall-runoff structures, tested on numerous watersheds, exploiting diverse rainfall-runoff transformation concepts and soil moisture accounting processes (e.g. linear, non-linear, multilayer, etc.). They are also designed to take into account many contributions to the total flow, based on storages (also called buckets) and interconnections, as well as flow routing delay (e.g. unit hydrogram, time laps, etc.). In some cases, when the sensitivity was considered small, their designers have fixed some of their parameters in order to favour the parsimony of the models, reducing computation 

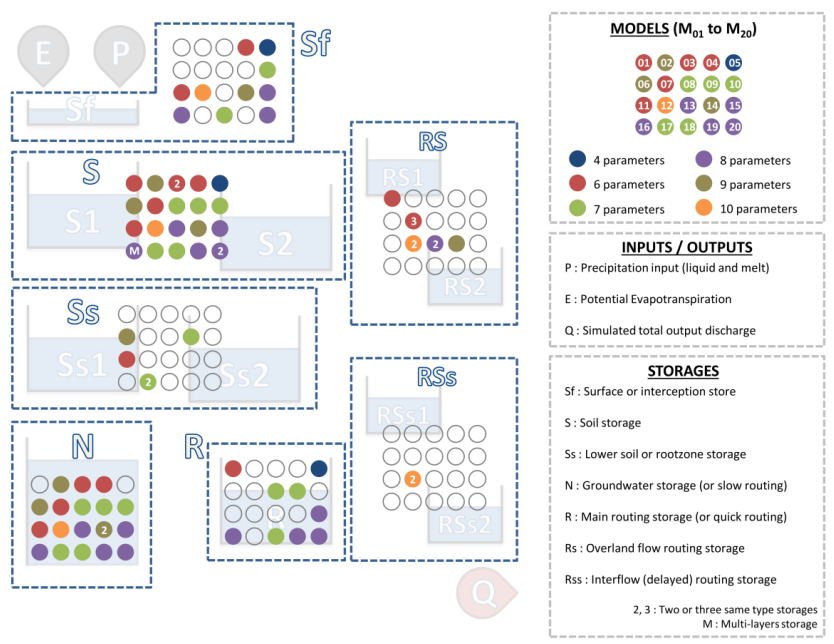

Figure 2. Illustration of the structural diversity of the twenty lumped conceptual models.

time and equifinality issues. These models, or part of, were exploited by Velázquez et al. (2010) for exploring multimodel ensemble forecasting and by Seiller et al. (2012) for assessing the robustness of the ensemble under contrasted climate.

Twenty conceptual lumped hydrological models (M01 to M20) were tested (see Table 1). They rely on four to ten free parameters and on two to seven storages - the number of storages correspond to the ones structuring the model and consequently they do not all participate directly to the routing. In the same way, it was recognised that interception function can be assimilated as a "surface storage". Figure 2 illustrates the structural diversity of the selected models. It informs on their inputs and output, as well as on the different types of storages: surface, soil, root zone, groundwater, main routing, delayed routing, etc. All models were applied in exactly the same conditions and run at a daily time step.

\subsubsection{Twenty-four potential evapotranspiration formulations}

Oudin et al. (2005), Singh and Xu (1997) and Xu and Singh $(1998,2000,2001,2002)$ provided a great source of inspiration for PET formulation selection. For instance, Oudin et al. (2005) implemented 27 PET formulations and four hydrological models on 308 catchments of diverse hydroclimatic conditions.

Twenty-four PET formulations (E01 to E24), adapted to our hydroclimatic context, were selected for this study. They are of three types: combinational (six), temperature-based (eight), and radiation-based (ten). Table 2 lists the formulas and related input data. Classification into families depends on the development philosophy more than their input data. For example, Priestley-Taylor formula (E04) is combinational even if wind speed is not explicitly used as an input, because it is a simplification of Penman formula (E01). On the opposite, Doorenbos-Pruitt formula (E20) is an adaptation of radiation-based formula E22 (Makkink), even if wind speed is used as an input data. All of them originate from various regional contexts and development objectives, but our selection aims to cover a large spectrum of concepts in order to favour diversity.

Empirical coefficients have been set for the au Saumon catchment, based on recent developments and applications. Shared parameters or variables have been computed based on EWRI-ASCE (Environmental \& Water Resources Institute American Society of Civil Engineers) report recommendations (Allen et al., 2005).

\subsubsection{Seven snow modules}

Valéry (2010) studied existing snow modules from a hydrological (streamflow) point of view, before proposing a novel one: CemaNeige. The latter originates from a comprehensive database composed of 380 watersheds exposed to diverse Nordic meteorological and geographical conditions in Sweden, France, Canada, and Switzerland. Parsimony, performance and robustness were the main objectives of the $\mathrm{Ce}$ maNeige development.

The degree-day based CemaNeige (Valéry, 2010; Nicolle et al., 2011) relies on two free-parameters: $K_{\mathrm{f}}$, the melting rate $\left(\mathrm{mm}^{\circ} \mathrm{C}^{-1}\right)$ and $C_{\mathrm{Tg}}$, the snowpack thermal state coefficient (no unit), and on two state variables: $G$, the snowpack in $\mathrm{mm}$ and eTg, the snowpack thermal state in ${ }^{\circ} \mathrm{C}$. CemaNeige exploits five altitudinal layers of equal area. Its precipitation partition, between solid and liquid, can be computed by two different formulations, depending on the layer altitude. Liquid precipitation is directly by-passed to the hydrological model, whereas solid precipitation is cumulated in the snowpack $G$. The thermal state of the snowpack is calculated with air temperature and $C_{\mathrm{Tg}}$ coefficient. Melt depends on degreeday and is only activated when temperature is above the melt temperature (fixed at $0^{\circ} \mathrm{C}$ ) and depending on the $K_{\mathrm{f}}$ parameter. Effective melt $\left(\mathrm{mm} \mathrm{day}^{-1}\right)$ is put into the hydrological model.

Valéry's thesis details the many concepts and structures considered during the development process of CemaNeige (N1). Inspired by a parsimonious bottom-up point of view, a concept or structure was only retained in CemaNeige if it substantially improved the hydrological performance over most of the 380 tested watersheds. It is thus opted in the present study to explore some of these rejected concepts, functions, and parameters in order to develop six alternative snow modules (N2 to N7) of various structural levels of complexity. Individual concepts (i.e. air temperature, melt temperature, precipitation separation, melting rate, melt weighting, altitudinal layering, thermal state, melt routing, precipitation correction, liquid water retention, and heat due to rain) were compared in order to compile the six new versions (see Fig. 3 and Table 3). Selection is a compromise 
Table 1. List of the twenty lumped conceptual models and their source of inspiration.

\begin{tabular}{lcrrl}
\hline & & Free & & \\
Name & Acronym & parameters & Storages & Derived from \\
\hline M01 & BUCK & 6 & 3 & BUCKET (Thornthwaite and Mather, 1955) \\
M02 & CEQU & 9 & 2 & CEQUEAU (Girard et al., 1972) \\
M03 & CRE0 & 6 & 3 & CREC (Cormary and Guilbot, 1973) \\
M04 & GARD & 6 & 3 & GARDENIA (Thiery, 1982) \\
M05 & GR4J & 4 & 3 & GR4J (Perrin et al., 2003) \\
M06 & HBV0 & 9 & 3 & HBV (Bergström and Forsman, 1973) \\
M07 & HYMO & 6 & 5 & HYMOD (Wagener et al., 2001) \\
M08 & IHAC & 7 & 3 & IHACRES (Jakeman et al., 1990) \\
M09 & MART & 7 & 4 & MARTINE (Mazenc et al., 1984) \\
M10 & MOHY & 7 & 3 & MOHYSE (Fortin and Turcotte, 2007) \\
M11 & MORD & 6 & 4 & MORDOR (Garçon, 1999) \\
M12 & NAM0 & 10 & 7 & NAM (Nielsen and Hansen, 1973) \\
M13 & PDM0 & 8 & 4 & PDM (Moore and Clarke, 1981) \\
M14 & SACR & 9 & 5 & SACRAMENTO (Burnash et al., 1973) \\
M15 & SIMH & 8 & 4 & SIMHYD (Chiew and Siriwardena, 2005) \\
M16 & SMAR & 8 & 4 & SMARY et SMARG (O'Connell et al., 1970) \\
M17 & TAN0 & 7 & 4 & TANK (Sugawara, 1979) \\
M18 & TOPM & 7 & 4 & TOPMODEL (Beven and Kirkby, 1979) \\
M19 & WAGE & 8 & 3 & WAGENINGEN (Warmerdam et al., 1997) \\
M20 & XINA & 8 & 5 & XINANJIANG (Zhao et al., 1980) \\
\hline
\end{tabular}

Table 2. List of the twenty-four PET formulations per category: combinational, temperature-based, and radiation-based.

\begin{tabular}{lcll}
\hline PET Class & Short name & Formulation name & Required data \\
\hline & E01 & Penman & $\mathrm{RH}, T, U, R_{\mathrm{S}}$ \\
& E02 & Penman-Monteith & $\mathrm{RH}, T, U, R_{\mathrm{S}}$ \\
E03 & FAO56 P-M (ASCE) & $\mathrm{RH}, T, U, R_{\mathrm{S}}$ \\
& E04 & Priestley-Taylor & $T, R_{\mathrm{S}}$ \\
& E05 & Kimberly-Penman & $\mathrm{RH}, T, U, R_{\mathrm{S}}$ \\
& E06 & Thom-Oliver & $\mathrm{RH}, T, U, R_{\mathrm{S}}$ \\
\hline & E07 & Thornthwaite & $T$ \\
& E08 & Blaney-Criddle & $T, R_{\mathrm{S}}$ \\
& E09 & Hamon & $T, R_{\mathrm{S}}$ \\
& E10 & Romanenko & $\mathrm{RH}, T$ \\
E11 & Linacre & $\mathrm{RH}, T$ \\
& E12 & MOHYSE & $T$ \\
& E13 & Hydro-Québec (HSAMI) & $T$ \\
& E14 & Kharrufa & $T$ \\
\hline & E15 & Wendling (WASIM) & $T, R_{\mathrm{S}}$ \\
& E16 & Turc & $\mathrm{RH}, T, R_{\mathrm{S}}$ \\
E17 & Jensen-Haise & $T$ \\
& E18 & McGuinness-Bordne & $T$ \\
& E19 & Hargreaves & $T$ \\
E20 & Doorenbos-Pruitt & $\mathrm{RH}, T, U, R_{\mathrm{S}}$ \\
& E21 & Abtew & $\mathrm{RH}, T, R_{\mathrm{S}}$ \\
& E22 & Makkink & $T$ \\
E23 & Oudin & $T$ \\
\hline E24 & Baier-Robertson & $T$ \\
\hline
\end{tabular}

with RH: relative humidity; $T$ : temperature; $U$ : wind speed; $R_{\mathrm{S}}$ : incoming solar radiation. 
between performance (close or above CemaNeige' ones for the au Saumon catchment) and internal diversity (snowpack, solid precipitations, thermal state, and effective melt).

\subsection{Model calibration}

Hydrological model calibration is achieved over the entire observed data set (i.e. from 1975 to 2003) - differential split sample tests were performed in Seiller et al. (2012). It relies on the Shuffled Complex Evolution (SCE) algorithm (Duan and Gupta, 1992; Duan et al., 1994), a robust heuristic automatic optimisation tool (error minimisation) that is common in hydrological sciences and is known for its performance (e.g. Wang et al., 2009). The SCE proceeds in five steps over the entire parametric space by generating an initial parameter population, ranking results, partitioning into complexes, evolving complexes, and recombining them until the convergence criteria is reached. Here, the objective function is the Nash-Sutcliffe efficiency (Nash and Sutcliffe, 1970) computed on root-squared discharges $\left(\mathrm{NSE}_{\text {sqrt }}\right)$ :

$\mathrm{NSE}_{\mathrm{sqrt}}=1-\frac{\sum_{i=1}^{N}\left(\sqrt{Q_{\text {sim }, i}}-\sqrt{Q_{\mathrm{obs}, i}}\right)^{2}}{\sum_{i=1}^{N}\left(\sqrt{Q_{\mathrm{obs}, i}}-\overline{\sqrt{Q_{\mathrm{obs}}}}\right)^{2}}$

with $Q_{\mathrm{obs}, i}$ and $Q_{\mathrm{sim}, i}$ respectively the observed and simulated discharges at time step $i$ and $N$ the total number of observations. Criteria on root-squared discharges are considered as multi-purpose, evaluating global deviation between observed and simulated discharges with a lesser emphasis on high flow discharges than the standard NSE on nontransformed discharges (Chiew and McMahon, 1994; Oudin et al., 2006).

3360 calibrated parameter sets (i.e. one for each hydrological model/PET/snow module combination) are then available for reference simulations (REF, 1970-2000) and future projections (FUT, 2041-2070). Such methodology assumes that the parameter sets are compatible for current and future climatic conditions, addressing the issue of transposability. Transposability in time, on contrasted climatic conditions, is discussed for the same catchment and models in Seiller et al. (2012).

\subsection{Uncertainty assessment of hydroclimatic simulations and projections}

Current simulations (or calibration, CAL), reference simulations (REF) and future projections (FUT) consist in a large number of time series. They exploit the 3360 parameter sets, which lead to:

- 3360 simulations $(20 \mathrm{M} \times 24 \mathrm{E} \times 7 \mathrm{~N})$ for the observed period

- 16800 simulations $(20 \mathrm{M} \times 24 \mathrm{E} \times 7 \mathrm{~N} \times 5 \mathrm{C})$ for the reference period

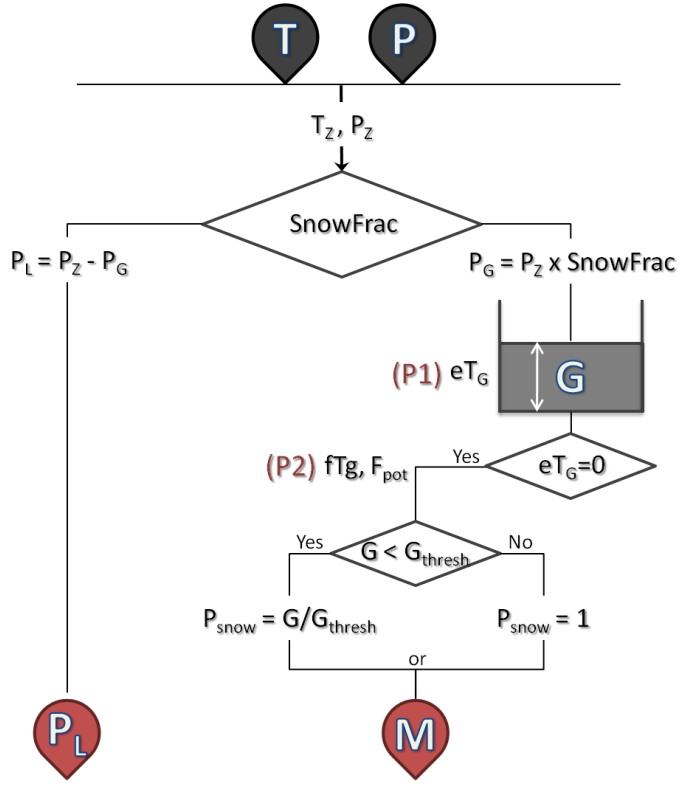

Figure 3. Initial version of the CemaNeige snow module (N1). $T$ is temperature, $P$ is total precipitation, $P_{\mathrm{L}}$ is liquid precipitation, $P_{G}$ is solid precipitation, and $M$ is snowmelt. $G$ corresponds to the snowpack and $\mathrm{P} 1$ and $\mathrm{P} 2$ are the two free parameters (modified from Valéry, 2010).

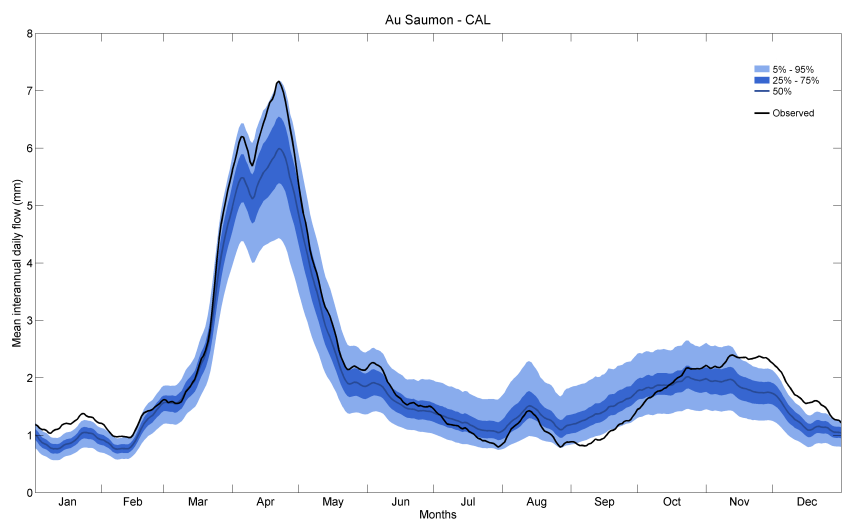

Figure 4. Cumulative uncertainties for the observed period simulation. The black line is the observed flow, the blue line depicts the median flow simulation, and the pale and dark blue envelopes, the distribution of the streamflow ensemble ( 5 to $95 \%$ and 25 to $75 \%$, respectively).

- 16800 projections $(20 \mathrm{M} \times 24 \mathrm{E} \times 7 \mathrm{~N} \times 5 \mathrm{C})$ for the future period

After the appraisal of the calibration performance on the Nash-Sutcliffe efficiency, to illustrate the effects of modelling tools selection on the calibration process, an uncertainty assessment is performed mainly based on these simulated and projected hydrographs and resulting hydrological indicators (overall mean flow, OMF). 
Table 3. List of the seven snow module versions and free-parameters.

\begin{tabular}{|c|c|c|}
\hline Name & $\begin{array}{c}\text { Free } \\
\text { parameters }\end{array}$ & Version details \\
\hline $\mathrm{N} 1$ & 2 & $\begin{array}{l}\text { Initial CemaNeige version (Valéry, 2010) } \\
\mathrm{P} 1: C_{\mathrm{Tg}} ; \mathrm{P} 2: K_{\mathrm{f}}\end{array}$ \\
\hline $\mathrm{N} 2$ & 4 & $\begin{array}{l}\text { Modified version (sinusoidal } K_{\mathrm{f}}, T_{\mathrm{f}}=-1{ }^{\circ} \mathrm{C} \text {, modified SnowFrac function, eTG } \\
\text { depending on air temp., progressive melt, free } \mathrm{TG}_{\mathrm{thresh}} \text { ) } \\
\mathrm{P} 1: C_{\mathrm{Tg}} ; \mathrm{P} 2: \min K_{\mathrm{f}} ; \mathrm{P} 3: \max K_{\mathrm{f}} ; \mathrm{P} 4: \mathrm{TG}_{\mathrm{thresh}}\end{array}$ \\
\hline $\mathrm{N} 3$ & 5 & $\begin{array}{l}\text { Modified version (linear SnowFrac with free parameters added, free thermal coeff } C_{\mathrm{t}} \text { ) } \\
\text { P1: Coeff } G ; \mathrm{P} 2: K_{\mathrm{f}} ; \mathrm{P} 3: C_{\mathrm{t}} ; \mathrm{P} 4: \text { int; P5: } T_{50}\end{array}$ \\
\hline N4 & 4 & $\begin{array}{l}\text { Modified version (modified SnowFrac function, free thermal coeff } C_{\mathrm{t}} \text {, free } G_{\text {thresh }} \text { ) } \\
\text { P1: } C_{\mathrm{Tg}} ; \mathrm{P} 2: K_{\mathrm{f}} ; \mathrm{P} 3: C_{\mathrm{t}} ; \mathrm{P} 4: G_{\text {thresh }}\end{array}$ \\
\hline N5 & 5 & $\begin{array}{l}\text { Modified version }\left(T_{\mathrm{f}}=-1{ }^{\circ} \mathrm{C} \text {, sinusoidal } K_{\mathrm{f}} \text {, modified SnowFrac function, free thermal }\right. \\
\left.\text { coeff } C_{\mathrm{t}} \text {, eTG depending on air temp., progressive melt, free } \mathrm{TG}_{\mathrm{thresh}}\right) \\
\mathrm{P} 1: C_{\mathrm{Tg}} ; \mathrm{P} 2: \min K_{\mathrm{f}} ; \mathrm{P} 3: \max K_{\mathrm{f}} ; \mathrm{P} 4: C_{\mathrm{t}} ; \mathrm{P} 5: \mathrm{TG}_{\mathrm{thresh}}\end{array}$ \\
\hline N6 & 1 & $\begin{array}{l}\text { Modified version (modified SnowFrac function, eTG not used) } \\
\text { P1: } K_{\mathrm{f}}\end{array}$ \\
\hline $\mathrm{Nh} 7$ & 2 & $\begin{array}{l}\text { Modified version ( } 50 \text { layers, sinusoidal } K_{\mathrm{f}} \text {, modified SnowFrac function) } \\
\mathrm{P} 1: C_{\mathrm{Tg}} ; \mathrm{P} 2: K_{\mathrm{f}}\end{array}$ \\
\hline
\end{tabular}

Cumulative streamflow uncertainty is evaluated first, representing the total uncertainty including hydrological models, PET formulations, snow modules, and climatic members. This step is performed on the CAL period where the measured discharges are available and then on REF and FUT periods to illustrate if this uncertainty varies with the simulated or projected period with climatic inputs.

Additionally, on the CAL period, it may be helpful to explore the reliability of the quantiles' envelopes, empirically drawn from the 3360 simulations, to comment if the latter can be directly interpreted as confidence intervals. The concept of a confidence interval reliability diagram consists in verifying if the observed relative frequency corresponds to the simulated one; perfect reliability would result in a $1: 1$ slope on the diagram (Wilks, 1995). Several confidence intervals are thus plotted (from 0.1 to 0.9 ) with, for example, 0.5 corresponding to the quartiles spread (25 to $75 \%$ ) and 0.9 corresponding to the spread of the 5 to $95 \%$ quantiles. Thus, for each of the 3360 simulations and each confidence interval, statement if observed discharge is included or not is verified, resulting in a reliability graph (Boucher et al., 2009; Velázquez et al., 2010).

Streamflow uncertainty is then evaluated for each modelling process (i.e. hydrological, PET, snow, natural climatic variability) based on hydrological indicators, namely the overall mean flow (OMF), corresponding to averaged daily flow for the entire simulation period. A process-based streamflow uncertainty is then available, allowing comments about its extent on the observation period and about its change from REF to FUT periods.

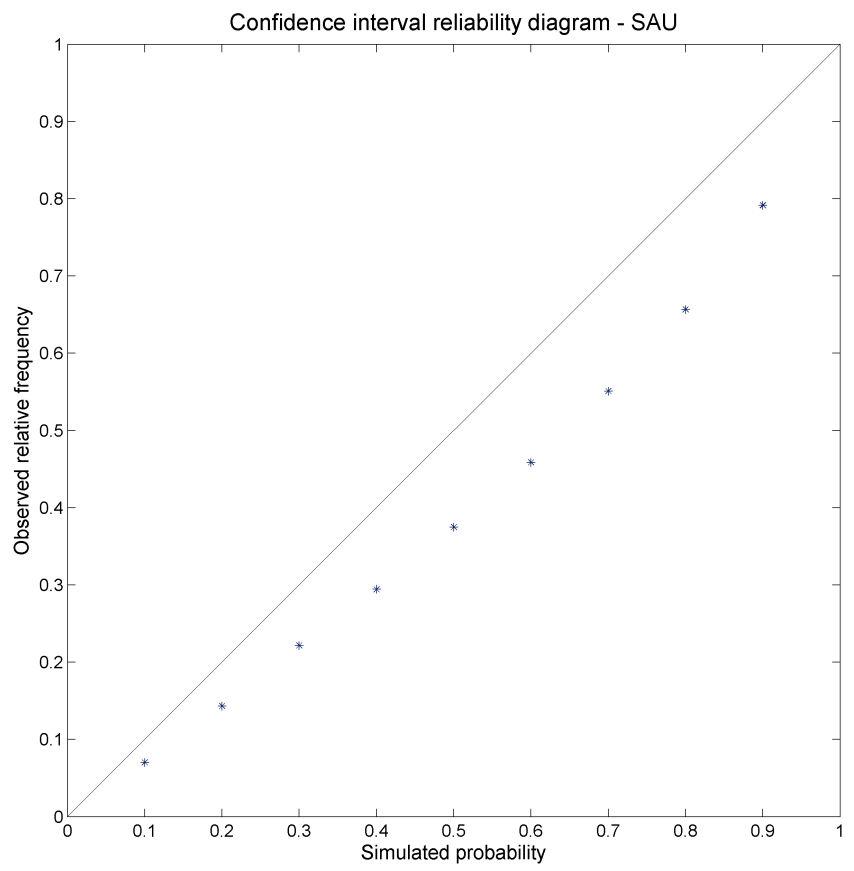

Figure 5. Confidence interval reliability diagram opposing simulated probability ( $x$ axis) and observed relative frequency ( $y$ axis). 


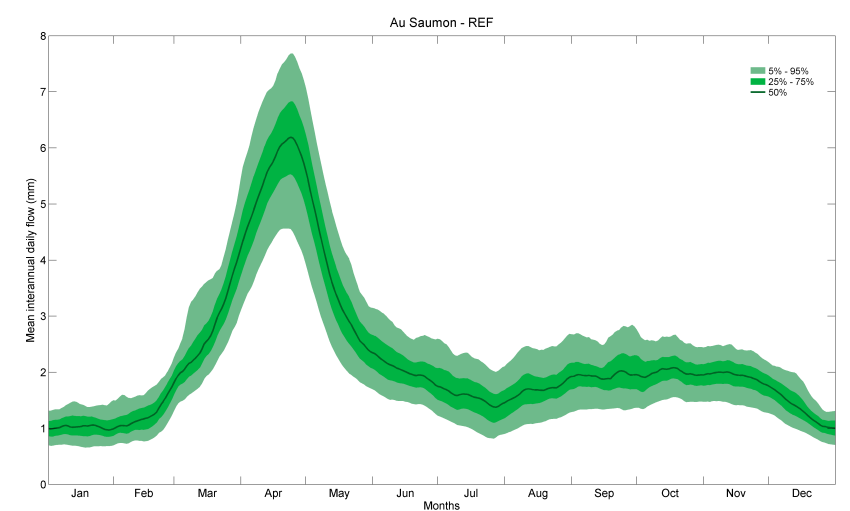

Figure 6. Cumulative uncertainties of the reference (REF) simulations. The line depicts the median flow simulation and the pale and dark green envelopes, the distribution of the streamflow ensemble ( 5 to $95 \%$ and 25 to $75 \%$, respectively).

All these steps highlight the influences of climate change on water resources, but mostly evaluate the uncertainty in our diagnosis, related to hydrological modelling and natural internal variability of simulated climate system.

\section{Results}

\subsection{Calibration performance}

Table 4 summarizes the outcome of the calibration in terms of $\mathrm{NSE}_{\mathrm{sqrt}}$ for each hydrological tool, providing median values and 5th and 95th percentiles (in brackets). The hydrological model section (M01 to M20) pools 168 values per model, the PET formulation section (E01 to E24) embeds 140 values per formulation, while the snow module section (N1 to N7) groups 480 values per module. The best performance is achieved by M05, with a median $\mathrm{NSE}_{\text {sqrt }}$ of 0.81 , while M02 (0.56) and M13 (0.57) rank last. E12 (0.66) is the less efficient PET formulation while E23 (0.78) is prevalent. It should be highlighted that PET performance is less contrasted than for the hydrological models. Snow modules are quite uniform in terms of performance (0.75), except $\mathrm{N} 7$ that is lesser $(0.71)$. The overall performance is quite satisfying and shows a great adequacy between the observed and simulated discharge on the au Saumon catchment.

\subsection{Cumulative streamflow uncertainty}

\subsubsection{Observation simulation}

Assessment of the observation total cumulative uncertainty illustrates the diversified response of our individual modelling tools on a period for which discharges are available. Initial modelling miscues may thus be identified and characterised, on an interannual average daily basis.

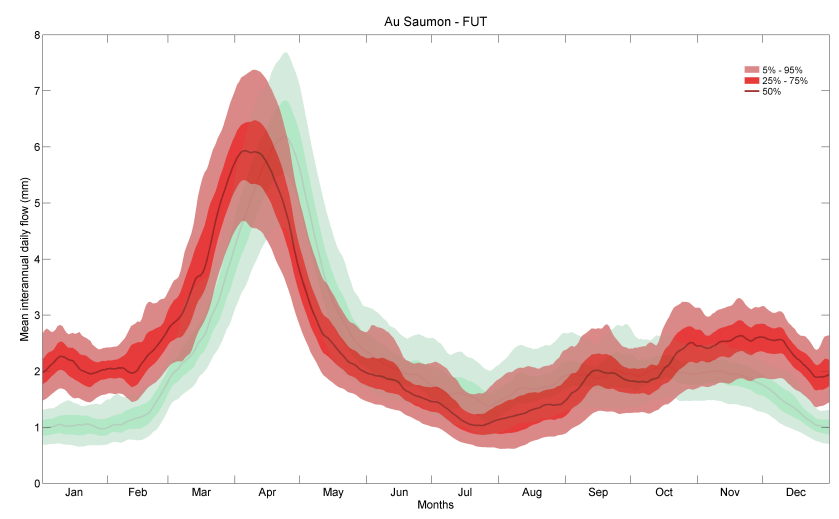

Figure 7. Cumulative uncertainties of the future (FUT) projection. The line depicts the median flow projection and the pale and dark red envelopes, the distribution of the streamflow ensemble ( 5 to $95 \%$ and 25 to $75 \%$, respectively). REF simulation is displayed transparently in green colour.

The cumulative uncertainty on the au Saumon catchment is illustrated in Fig. 4: the pale and dark blue envelopes illustrate the distribution of the streamflow ensemble ( 5 to $95 \%$ and 25 to $75 \%$, respectively), the blue line, the median flow, and the black line, the observed flow. Envelopes are drawn connecting daily discharges, using a moving average to smoother the lines. Observations fall within the 5 to $95 \%$ envelope except for a part of January (underestimation), a few days in September (overestimation) and from mid-November to the third week of December (underestimation). The highest uncertainty occurs during the most active hydrological period, namely the spring flood, with a maximum spread of $2.74 \mathrm{~mm}$ on 22 April (between 7.15 and $4.41 \mathrm{~mm}$ ). The smallest uncertainty ensues during the winter low flows, with a minimum spread of $0.37 \mathrm{~mm}$ on 10 February (between 0.96 and $0.59 \mathrm{~mm}$ ). These findings confirm that high flows are more complex to encompass than low flows, probably because of their irregular behaviour. However, the choice of an objective function based on root-squared transformed discharges may also provide an explanation for this specific behaviour. Still, it remains a relevant criterion for climate change impacts.

As mentioned in the material and methods section, exploration of the reliability of the quantiles' envelopes, empirically drawn from the 3360 simulations, aims at commenting if the latter can be directly interpreted as confidence intervals. For this purpose, a confidence interval reliability diagram is computed for the au Saumon catchment. Results in Fig. 5 reveal a slight under-dispersion, confirming a possible link between the envelopes drawn in Fig. 4 and confidence intervals.

These results confirm that the ability to simulate the precipitation-runoff transformation is hampered by the choice of lumped conceptual modelling tools. However, it can be questioned if this uncertainty is maintained, reduced 
or increased with climatic data as inputs and if it persists in future projections, affecting de facto our ability to report a diagnosis of the impacts of climate change on water resources.

\subsubsection{Climate simulation and projection}

Figures 6 and 7 present a similar hydrograph analysis for reference simulations (REF, green) and future projections (FUT, red), respectively, based on climate data. Streamflow uncertainty originates either from the hydrological modelling process or from the climate natural variability (members), as disclosed by 16800 simulations and projections. For REF (Fig. 6), as for the observations, the largest uncertainty occurs during spring flood with a maximum spread of $3.19 \mathrm{~mm}$ (between 7.53 and $4.34 \mathrm{~mm}$ ) on 26 April, while the smallest uncertainty takes place in winter, 27 December, when the spread falls to $0.56 \mathrm{~mm}$ (between 1.29 and $0.73 \mathrm{~mm}$ ). For FUT (Fig. 7), the largest uncertainty $(2.86 \mathrm{~mm})$ is reached on 19 April, with discharge oscillating between 6.84 and $3.98 \mathrm{~mm}$, and smallest uncertainty occurs 1 February, with a $0.81 \mathrm{~mm}$ spread (between 2.42 and $1.61 \mathrm{~mm}$ ). REF and FUT uncertainties are more important than simulation on the observed period, but the latter do not account for the climate natural variability (members). Envelops are more uniform over the year, when including the climate natural variability.

Evolution from REF to FUT reveals a spring flood arriving fifteen days earlier, with a slight decrease in the spring high flows. In addition, changes favour an increase of winter low flows and a decrease of summer low flows, demonstrating a substitution in time of the lowest flows.

This streamflow uncertainty analysis, based on interannual hydrographs combining the influence of the hydrological process and of the climate natural variability, reveals some adversity in our ability to produce a clear diagnosis of climate change impacts on water resources for the au Saumon catchment. Indeed, cumulative uncertainty envelopes are large, especially on hydrologically sensitive periods such as spring high flows and summer low flows.

\subsection{Process-based streamflow uncertainty}

Analysis of the cumulative uncertainty from yearly averaged hydrographs highlights the extent of the uncertainty in simulation and projection, but without providing much information about its origin. To assess this question in more details and to identify which modelling step contributed the most to the reported cumulative uncertainty, a water resources manager point of view is taken next, using a simple hydrological indicator: the overall mean flow (OMF). This process-based streamflow uncertainty is then computed on the observation period and on changes from REF to FUT periods.

\subsubsection{Observation OMF}

Figure 8 illustrates, by type of tools, the OMF uncertainty for simulations on the observation (calibration) period - 168 values per box plot for the lumped conceptual hydrological models, 140 values per box plot for the PET formulations, and 480 values per box plot for the snow modules - while the OMF total uncertainty shows 3360 values. In Fig. 8, coloured bars indicate the 25 and $75 \%$ quartiles of each distribution, while the horizontal white line identifies the median value. The latter can be associated with the uncertainty for each tool, while the interquartile range (e.g. blue bars for the models) can be perceived as depicting sensitivity and robustness. Finally, the observed OMF $(2.12 \mathrm{~mm})$ is illustrated by a red cross in the total uncertainty box. The latter is higher than most of the 3360 runs because, as already mentioned in the hydrographs analysis, the observed spring high flow is in general underestimated.

M04 median OMF $(2.13 \mathrm{~mm})$ is quite close to the observed one. It is however the highest median OMF out of 20. The lowest one is the M12 median OMF (1.83 mm), disclosing the range of the uncertainty emanating from the lumped conceptual models and the importance of selecting the right model if exploiting only one structure. It can also be pointed out that M05 and M08 generate reduced inner sensitivity (i.e. smaller interquartile ranges), while the opposite is true for M12 and M07.

PET OMFs divulge an even higher uncertainty than for the lumped conceptual models. Indeed, their median OMF range from 2.48 (E02) to $1.79 \mathrm{~mm}$ (E20), largely encompassing the observed OMF (red cross), but also stressing the necessity of selecting an appropriate PET formulation. The PET inner sensitivities (extent of the green bar) also vary considerably from one another, the largest and smallest ranges originating from E02 and E23, respectively. Note finally that some PET OMF distributions are quite asymmetrical, namely for E01, $\mathrm{E} 02, \mathrm{E} 03, \mathrm{E} 04, \mathrm{E} 06$, and E10, combination formulations for most of them.

If the selection of a particular lumped conceptual model and of a particular PET formulation have a huge impact on the OMF uncertainty, it is clearly not the case for the seven selected snow modules, which interquartile ranges and median OMFs, extending from 1.96 (N1) to $1.95 \mathrm{~mm}(\mathrm{~N} 7)$, are all quite similar.

\subsubsection{OMF relative change}

A similar analysis is performed on the OMF relative change from REF to FUT $\left[100 \times\left(\mathrm{OMF}_{\mathrm{FUT}}-\mathrm{OMF}_{\mathrm{REF}}\right) / \mathrm{OMF}_{\mathrm{REF}}\right.$, in $\%$ ], drawing box plots (Fig. 9) for each modelling process and for each climatic member (red), the latter in order to depict the climate natural variability - each member originated from the same GCM initiated with slightly modified initial conditions in 1850, expressing the chaotic nature of the climate. Total OMF uncertainty then combines 16800 relative changes, 840 ones per lumped conceptual model, 700 per PET formulation, 2400 per snow module, and finally 3360 per climatic member. Focus is again mainly given to 


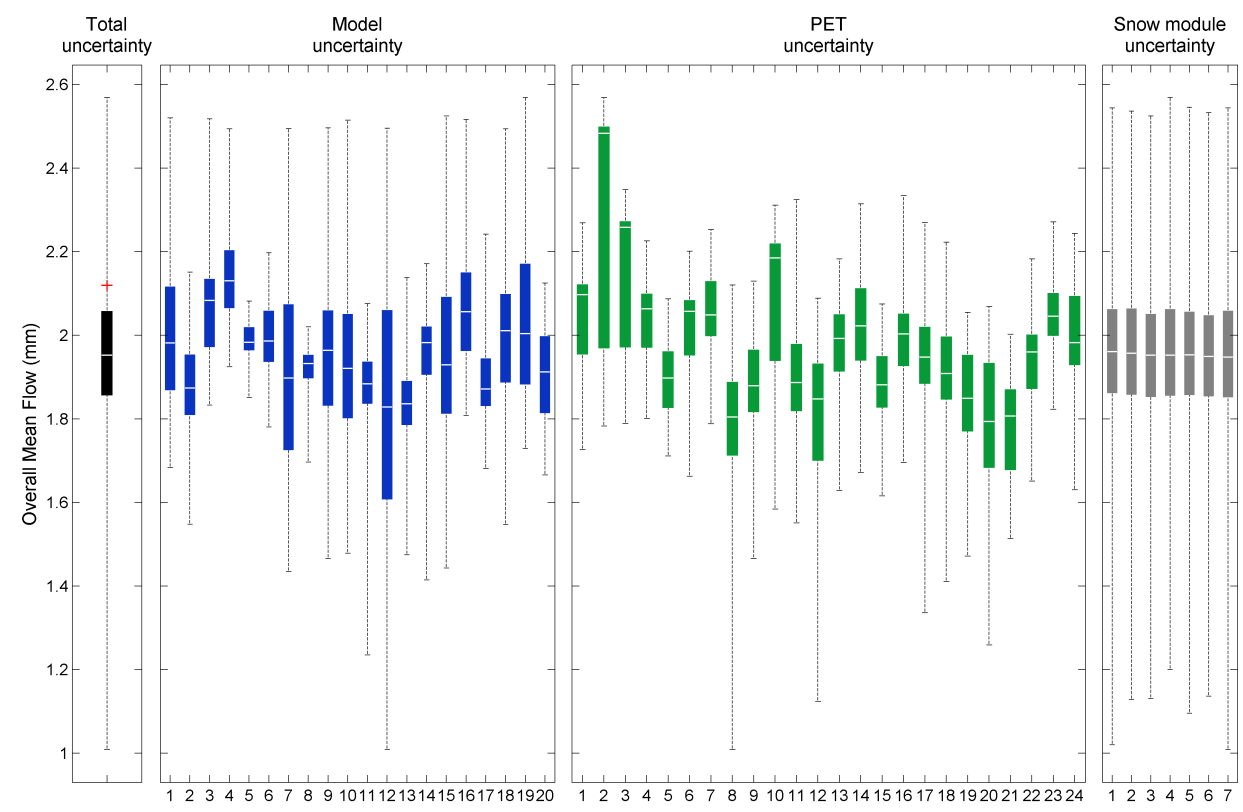

Figure 8. Total (black box plot) and process-based overall mean flow (OMF, mm) uncertainty, for simulation on the observed period. The observed OMF is illustrated by a red cross in the total uncertainty box. Blue box plots correspond to the lumped conceptual hydrological models, green box plots to the PET formulations and grey box plots to the snow modules.

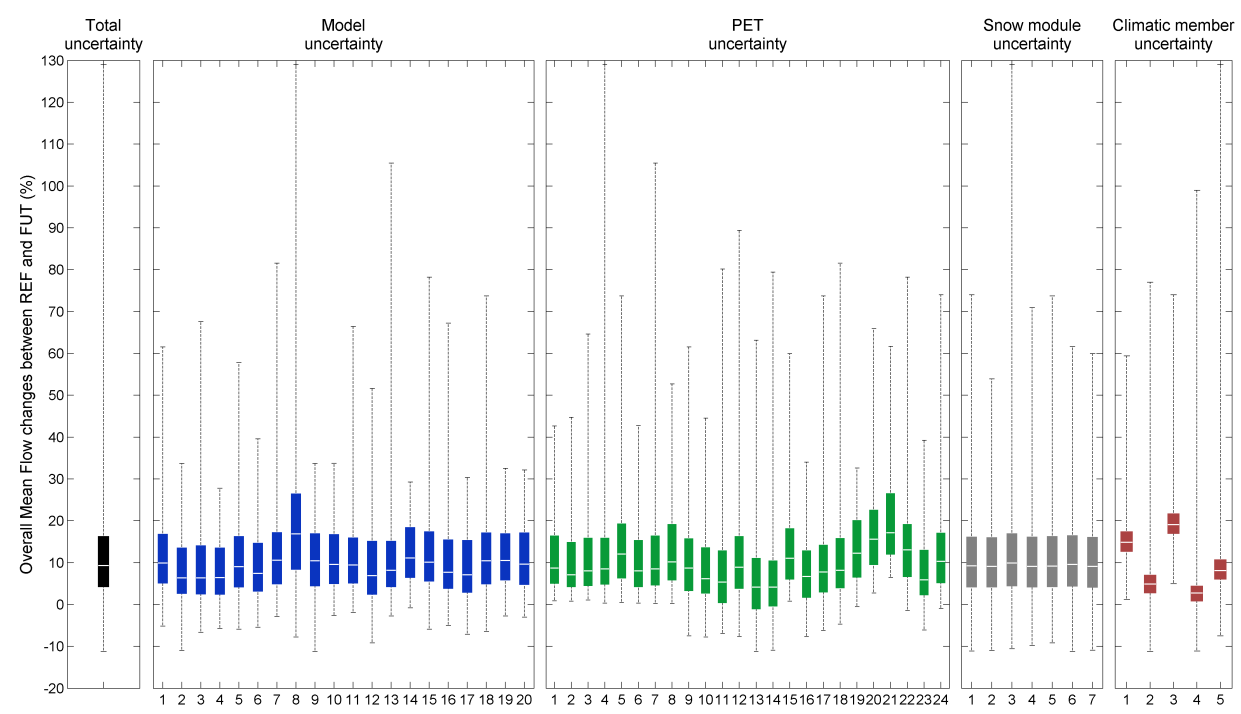

Figure 9. Total (black box plot), process-based, and climate overall mean flow evolution (from REF to FUT, \%) uncertainty. Blue box plots correspond to the lumped conceptual hydrological models, green box plots to the PET formulations, grey box plots to the snow modules and red box plots to the climatic members.

median values (uncertainty) and interquartile ranges (inner sensitivity).

The total OMF relative change fluctuates from -11 to + $129 \%$, but its interquartile range is restrained from +4.2 to $+16.2 \%$, with a median value of $+9.3 \%$. This total uncertainty is distributed between conceptual hydrological modelling tools (namely PET, hydrological models, and snow modules) and climatic members.
The median OMF relative change per lumped conceptual model fluctuates from +6.3 (M02) to $+16.8 \%$ (M08), confirming the sensitivity to the lumped conceptual model selection. The interquartile range is more uniform from one model to the other than in Fig. 8, but M08 differs (18.1\%) in that regard - M08 was already identified with poor transposability on the same catchment by Seiller et al. (2012). The lowest inner sensitivity is achieved by M11 (10.9\%). PET 
Table 4. Characteristics of the calibration performance ( $\mathrm{NSE}_{\mathrm{sqrt}}$ ) pooled by hydrological models, PET formulations and snow modules. Bold corresponds to the best performing options, when italic is the worst option.

\begin{tabular}{|c|c|c|c|c|c|}
\hline \multicolumn{2}{|c|}{ Hydrological model } & \multicolumn{2}{|c|}{ PET formulation } & \multicolumn{2}{|c|}{ Snow module } \\
\hline Name & Median (5th, 95th) & Name & Median (5th, 95th) & Name & Median (5th, 95th) \\
\hline M01 & $0.76(0.67,0.79)$ & E01 & $0.76(0.56,0.80)$ & N1 & $0.75(0.53,0.81)$ \\
\hline M02 & $0.56(0.48,0.62)$ & E02 & $0.70(0.50,0.78)$ & $\mathrm{N} 2$ & $0.75(0.53,0.81)$ \\
\hline M03 & $0.78(0.70,0.80)$ & E03 & $0.75(0.55,0.79)$ & $\mathbf{N 3}$ & $0.75(0.55,0.81)$ \\
\hline M04 & $0.77(0.68,0.79)$ & E04 & $0.76(0.58,0.81)$ & N4 & $0.75(0.55,0.80)$ \\
\hline M05 & $0.81(0.72,0.83)$ & E05 & $0.76(0.55,0.80)$ & N5 & $0.75(0.52,0.80)$ \\
\hline M06 & $0.76(0.69,0.78)$ & E06 & $0.75(0.56,0.79)$ & N6 & $0.75(0.56,0.80)$ \\
\hline M07 & $0.60(0.49,0.63)$ & E07 & $0.77(0.60,0.82)$ & $N 7$ & $0.71(0.52,0.79)$ \\
\hline M08 & $0.71(0.64,0.75)$ & E08 & $0.68(0.47,0.78)$ & & \\
\hline M09 & $0.76(0.64,0.80)$ & E09 & $0.76(0.53,0.81)$ & & \\
\hline M10 & $0.73(0.58,0.81)$ & E10 & $0.67(0.49,0.72)$ & & \\
\hline M11 & $0.74(0.63,0.80)$ & E11 & $0.74(0.54,0.80)$ & & \\
\hline M12 & $0.71(0.36,0.78)$ & E12 & $0.66(0.45,0.79)$ & & \\
\hline M13 & $0.57(0.47,0.65)$ & E13 & $0.77(0.58,0.81)$ & & \\
\hline M14 & $0.78(0.68,0.81)$ & E14 & $0.77(0.61,0.81)$ & & \\
\hline M15 & $0.75(0.62,0.79)$ & E15 & $0.75(0.56,0.79)$ & & \\
\hline M16 & $0.78(0.68,0.80)$ & E16 & $0.76(0.58,0.81)$ & & \\
\hline M17 & $0.76(0.68,0.80)$ & E17 & $0.75(0.56,0.80)$ & & \\
\hline M18 & $0.77(0.67,0.80)$ & E18 & $0.77(0.59,0.80)$ & & \\
\hline M19 & $0.76(0.65,0.81)$ & E19 & $0.75(0.56,0.81)$ & & \\
\hline \multirow[t]{5}{*}{ M20 } & $0.63(0.56,0.65)$ & E20 & $0.72(0.54,0.80)$ & & \\
\hline & & E21 & $0.69(0.49,0.76)$ & & \\
\hline & & E22 & $0.77(0.57,0.81)$ & & \\
\hline & & E23 & $0.78(0.59,0.82)$ & & \\
\hline & & E24 & $0.77(0.59,0.82)$ & & \\
\hline
\end{tabular}

OMF relative change is in general slightly higher than for the lumped conceptual models, from +4.1 (E13) to $+17.1 \%$ (E21), stressing also the sensitivity to the selection of a PET formulation. The highest interquartile range is obtained by E21 (14.5\%), and the lowest by E02 (10.6\%). Again, the behaviour of the snow modules is more uniform than for the lumped conceptual models and for the PET formulations. The median OMF relative change of the snow modules are limited from $+9.1(\mathrm{~N} 2)$ to $+9.9 \%(\mathrm{~N} 3)$, while their interquartile ranges vary from $12.5(\mathrm{~N} 3)$ to $11.9 \%(\mathrm{~N} 2)$.

On the other hand, the behaviour of the climatic members is quite distinct. First, the interquartile ranges of their OMF relative change are much reduced when compared to the others: from $4.8(\mathrm{C} 1)$ to $3.6 \%$ (C4), expressing lower inner sensitivity. Second, their median OMF relative changes vary considerably: between +2.7 (C4) and $+19.1 \%$ (C3). This latter characteristic exemplifies the importance of the climatic natural variability. Changes differ greatly from one climatic member to the other. It is thus evident that a single 30 year realisation of the climate is insufficient to depict all the possible variability. Furthermore, it is also striking that an important part of the uncertainty spread revealed by the various hydrological processes actually originates from the climatic natural variability.
The example of this application to the au Saumon catchment demonstrates the limit of our ability to provide a clear diagnosis of climate change impacts on water resources, especially when looking at the total OMF relative change, combining 16800 simulations and projections. From these results, climatic natural variability is the first uncertainty driver, followed by PET formulations, lumped conceptual models, and snow modules, as depicted by the standard deviations of the median OMF relative change (Table 5), with respective values of $6.9,3.3,2.4$, and $0.3 \%$.

Since snow accumulation and melt are important hydrological processes on the au Saumon catchment, standard deviations of the median OMF relative change are also provided in Table 5 distinguishing months with mean interannual air temperature above $0^{\circ} \mathrm{C}$ (April to October) from months with mean interannual air temperature below $0^{\circ} \mathrm{C}$ (November to May). This distinction has only a small influence on the respective standard deviation values and none on the ranking of the uncertainty sources. 
Table 5. Characteristics of the median OMF relative change for different processes and periods.

\begin{tabular}{lccc}
\hline & Lowest value & Highest value & Standard deviation \\
\hline OMF & & & \\
\hline Hydrological model & $+6.3 \%(\mathrm{M} 02)$ & $+16.8 \%(\mathrm{M} 08)$ & $2.4 \%$ \\
PET formulation & $+4.1 \%(\mathrm{E} 13)$ & $+17.1 \%(\mathrm{E} 21)$ & $3.3 \%$ \\
Snow module & $+9.1 \%(\mathrm{~N} 2)$ & $+9.9 \%(\mathrm{~N} 3)$ & $0.3 \%$ \\
Climatic member & $+2.7 \%(\mathrm{C} 4)$ & $+19.1 \%(\mathrm{C} 3)$ & $6.9 \%$ \\
\hline April to October OMF & & & \\
\hline Hydrological model & $-14.2 \%(\mathrm{M} 06)$ & $-4.1 \%(\mathrm{M} 08)$ & $2.4 \%$ \\
PET formulation & $-15.8 \%(\mathrm{E} 14)$ & $-1.7 \%(\mathrm{E} 21)$ & $3.1 \%$ \\
Snow module & $-11.3 \%(\mathrm{~N} 1)$ & $-10.1 \%(\mathrm{~N} 6)$ & $0.5 \%$ \\
Climatic member & $-19.5 \%(\mathrm{C} 2)$ & $-2.4 \%(\mathrm{C} 3)$ & $7.6 \%$ \\
\hline November to May OMF & & & \\
\hline Hydrological model & $+17.1 \%(\mathrm{M} 17)$ & $+27.5 \%(\mathrm{M} 08)$ & $2.1 \%$ \\
PET formulation & $+14.1 \%(\mathrm{E} 14)$ & $+32.2 \%(\mathrm{E} 21)$ & $4.0 \%$ \\
Snow module & $+20.5 \%(\mathrm{~N} 1)$ & $+21.1 \%(\mathrm{~N} 6)$ & $0.3 \%$ \\
Climatic member & $+15.7 \%(\mathrm{C} 4)$ & $+26.3 \%(\mathrm{C} 3)$ & $4.7 \%$ \\
\hline
\end{tabular}

\section{Discussion and conclusion}

This paper explored uncertainties related to the hydrological modelling of climate change impacts on water resources. In particular, twenty lumped conceptual hydrological models, twenty-four PET formulations, and seven snow modules were assessed in order to evaluate our skill diagnosing the impacts of climate change on the hydrologic regime of a river. Natural climate variability, through climatic members, was also studied for comparison with the diverse hydrological structures.

Analysis on uncertainties illustrates that streamflow simulation over the current climate period (calibration) is already largely conditioned by the selection of hydrological tools, propagating this uncertainty on reference simulation and future projection. Results indicate that the largest source of uncertainty is associated with the natural climate variability, followed by PET formulations, lumped conceptual models, and snow modules. Calibration process and transposability questions thus appear as major issues for the calculation of future hydrological projections, but natural variability plays an even more substantial role in our ability to provide a diagnosis on the impacts of climate change on the hydrologic regime of a river, especially when exploiting hydrological indicators such as the OMF. Nonetheless, the fact that changes in the hydrologic regime of the au Saumon catchment differed greatly from one climatic member to the other; one has to question if a single 30 year realisation of the climate is sufficient to encompass all the possible variability.

This work focussed on only one Canadian catchment and must be confirmed with other watersheds and climate contexts, but the proposed methodology is easily transferable. Following climate natural variability, PET formulations add to the total uncertainty in a substantial way, but without much distinction between combinational, radiation-based, and temperature-based formulations. It must be acknowledged that PET equations, especially in this climate change context, also rely on empirical coefficients which add another source of uncertainty. Indeed, if different coefficients are selected for different locations under current climate, it is conceivable that different coefficients would also be appropriate for possible future climates in a catchment. This analysis could be extended on future work on this subject, as for example applied in Kay et al. (2013). Only lumped conceptual hydrological models were explored, mainly to limit implementation and computation time as well as parameter identification issues, but inclusion of several other model classes would be an important complementary contribution. Finally, uncertainties associated with snow modules turned out small for the current climate period as well as for the projections. It should be mentioned that the selected tools originated from the sane snow module (CemaNeige) re-designed in six other versions and that this approach may have affected the results. Here also, more diverse modules may be considered in further exploration of this issue.

Acknowledgements. The authors acknowledge NSERC, Ouranos, and Hydro-Québec for support, as well as partners in the $\mathrm{QBIC}^{3}$ (Quebec-Bavaria International Collaboration on Climate Change) project. We also thank the reviewers for their discussions, comments, and references.

Edited by: S. Attinger 


\section{References}

Allen, R. G., Walter, I. A., Elliott, R., Howell, T., Itenfisu, D., and Jensen, M.: The ASCE standardized reference Evapotranspiration equation, Final Report, p. 70, 2005.

Bae, D. H., Jung, I. W., and Lettenmaier, D. P.: Hydrologic uncertainties in climate change from IPCC AR4 GCM simulations of the Chungju Basin, Korea, J. Hydrol., 401, 90-105, 2011.

Bergström, S. and Forsman, A.: Development of a conceptual deterministic rainfall-runoff model, Nord. Hydrol., 4, 147-170, 1973.

Beven, K. J. and Kirkby, M. J.: A physically based variable contributing area model of basin hydrology, Hydrol. Sci. Bull., 24, 43-69, 1979.

Boé, J., Terray, L., Martin, E., and Habets, F.: Projected changes in components of the hydrological cycle in French river basins during the 21st century, Water Resour. Res., 45, 1-15, 2009.

Bormann, H.: Sensitivity analysis of 18 different potential evapotranspiration models to observed climatic change at German climate stations, Clim. Change, 104, 729-753, doi:10.1007/s10584010-9869-7, 2011.

Boucher, M.-A., Perreault, L., and Anctil, F.: Tools for the assessment of hydrological ensemble forecasts obtained by neural networks, J. Hydroinform., 11, 297-307, doi:10.2166/hydro.2009.037, 2009.

Boyer, C., Chaumont, D., Chartier, I., and Roy, A. G.: Impact of climate change on the hydrology of St. Lawrence tributaries, J. Hydrol., 384, 65-83, doi:10.1016/j.jhydrol.2010.01.011, 2010.

Burnash, R. J. C., Ferral, R. L., and McGuire, R. A.: A general streamflow simulation system?: Conceptual modeling for digital computers, U.S. Department of Commerce, National Weather Service and State of California, Department of Water Resources, p. 204, 1973.

Carter, T., Hulme, M., and Viner, D.: Representing uncertainty in climate change scenarios and impact studies, in Proceedings of the ECLAT-2 Helsinki Workshop, p. 128, 1999.

Chiew, F. H. S. and McMahon, T. A.: Application of the daily rainfall-runoff model MODHYDROLOG to 28 Australian catchments, J. Hydrol., 153, 383-416, 1994.

Chiew, F. H. S. and Siriwardena, L.: Estimation of SIMHYD parameter values for application in ungauged catchments, in MODSIM 2005 International Congress on Modelling and Simulation, Modelling and Simulation Society of Australia and New Zealand, Melbourne, Australia, 2883-2889, 2005.

Cormary, Y. and Guilbot, A.: Étude des relations pluie-débit sur trois bassins versants d'investigation, in IAHS Publication No.108 - Madrid Symposium, 265-279, Madrid, 1973.

Deser, C., Knutti, R., Solomon, S., and Phillips, A. S.: Communication of the role of natural variability in future North American climate, Nat. Clim. Chang., 2, 775-780, doi:10.1038/NCLIMATE1562, 2012.

Dettinger, M. D.: From climate-change spaghetti to climate-change distributions for 21st Century California, San Fr. Estuary Watershed Sci., 3, 1-14, 2005.

Duan, Q. and Gupta, V.: Effective and efficient global optimization for conceptual rainfall-runoff models, Water Resour., 28, 10151031, 1992.

Duan, Q., Sorooshian, S., and Gupta, V.: Optimal use of the SCEUA global optimization method for calibrating watershed models, J. Hydrol., 158, 265-284, 1994.
De Elía, R. and Côté, H.: Climate and climate change sensitivity to model configuration in the Canadian RCM over North America, Meteorol. Zeitschrift, 19, 325-339, doi:10.1127/09412948/2010/0469, 2010.

Fortin, V. and Turcotte, R.: Le modèle hydrologique MOHYSE, Quebec city, 2007.

Franz, K. J., Butcher, P., and Ajami, N. K.: Addressing snow model uncertainty for hydrologic prediction, Adv. Water Resour., 33, 820-832, 2010.

Garçon, R.: Modèle global pluie-débit pour la prévision et la prédétermination des crues, La Houille Blanche, 7, 88-95, 1999.

Gardner, L. R.: Assessing the effect of climate change on mean annual runoff, J. Hydrol., 379, 351-359, doi:10.1016/j.jhydrol.2009.10.021, 2009.

Girard, G., Morin, G., and Charbonneau, R.: Modèle précipitationsdébits à discrétisation spatiale, Cah. ORSTOM, Série Hydrol., IX, 35-52, 1972.

Görgen, K., Beersma, J., Brahmer, G., Buiteveld, H., Carambia, M., de Keizer, O., Krahe, P., Nilson, E., Lammersen, R., Perrin, C. and Volken, D.: Assessment of climate change impacts on discharge in the Rhine river basin?: Results of the RheinBlick2050 project, 2010.

Jakeman, A. J., Littlewood, I. G., and Whitehead, P. G.: Computation of the instantaneous unit hydrograph and identifiable component flows with application to two small upland catchments, J. Hydrol., 117, 275-300, 1990.

Jung, I. W., Bae, D. H., and Lee, B. J.: Possible change in Korean streamflow seasonality based on multi-model climate projections, Hydrol. Process., 13, 1033-1045, doi:10.1002/hyp.9215, 2012.

Kay, A. L. and Davies, H. N.: Calculating potential evaporation from climate model data: A source of uncertainty for hydrological climate change impacts, J. Hydrol., 358, 221-239, doi:10.1016/j.jhydrol.2008.06.005, 2008.

Kay, A. L., Davies, H. N., Bell, V. A., and Jones, R. G.: Comparison of uncertainty sources for climate change impacts: flood frequency in England, Clim. Change, 92, 41-63, doi:10.1007/s10584-008-9471-4, 2009.

Kay, A. L., Bell, V. A., Blyth, E. M., Crooks, S. M., Davies, H. N., and Reynard, N. S.: A hydrological perspective on evaporation: historical trends and future projections in Britain, J. Water Clim. Chang., 4, 193-208, doi:10.2166/wcc.2013.014, 2013.

Kiparsky, M. and Gleick, P. H.: Climate change and California water resources, in: The World's water 2004-2005, edited by: Gleick, P. H., 157-188, Island Press, Washington D. C., 2004.

Ludwig, R., May, I., Turcotte, R., Vescovi, L., Braun, M., Cyr, J.-F., Fortin, L.-G., Chaumont, D., and Biner, S.: The role of hydrological model complexity and uncertainty in climate change impact assessment, Adv. Geosci., 21, 63-71, 2009,

http://www.adv-geosci.net/21/63/2009/.

Mathevet, T.: Quels modèles pluie-débit globaux au pas de temps horaire?, 463 pp., École Nationale du Génie Rural, des Eaux et des Forêts, 2005.

Maurer, E. P.: Uncertainty in hydrologic impacts of climate change in the Sierra Nevada, California, under two emissions scenarios, Clim. Change, 82, 309-325, 2007. 
Mazenc, B., Sanchez, M., and Thiery, D.: Analyse de l'influence de la physiographie d'un bassin versant sur les paramètres d'un modèle hydrologique global et sur les débits caractéristiques à l'exutoire, J. Hydrol., 69, 97-118, 1984.

Minville, M., Brissette, F., and Leconte, R.: Uncertainty of the impact of climate change on the hydrology of a nordic watershed, J. Hydrol., 358, 70-83, 2008.

Moore, R. J. and Clarke, R. T.: A Distribution Function Approach to Rainfall Runoff Modeling, Water Resour. Res., 17, 1367-1382, 1981.

Nakicenovic, N., Alcamo, J., Davis, G., de Vries, B., Fenhann, J., Gaffin, S., Gregory, K., Grübler, A., Jung, T. Y., Kram, T., Lebre La Rovere, E., Michaelis, L., Mor, S., Morita, T., Pepper, W., Pitcher, H., Price, L., Riahi, K., Roehrl, A., Rogner, H.-H., Sankovski, A., Schlesinger, M., Shukla, P., Smith, S., Swart, R., van Rooijen, S., Victor, N. and Dadi, Z.: Emissions Scenarios. A Special Report of Working Group III of the Intergovernmental Panel on Climate Change, Cambridge University Press, Cambridge, UK, 2000.

Nash, J. E. and Sutcliffe, J. V.: River flow forecasting through conceptual models. Part I - A discussion of principles, J. Hydrol., 10, 282-290, 1970.

Nicolle, P., Ramos, M.-H., Andréassian, V., and Valéry, A.: Mieux prévoir les crues nivales?: Évaluation de prévisions probabilistes de débit sur des bassins versants de montagne français, in Colloque SHF?: "L'eau en montagne, mieux observer pour mieux prévoir,", 163-17, Société Hydrotechnique de France, Lyon, France, 2011.

Nielsen, S. A. and Hansen, E.: Numerical simulation of the rainfallrunoff process on a daily basis, Nord. Hydrol., 4, 171-190, 1973.

O’Connell, P. E., Nash, J. E., and Farrell, J. P.: River flow forecasting through conceptual models. Part II - The Brosna catchment at Ferbane, J. Hydrol., 10, 317-329, 1970.

Oudin, L., Hervieu, F., Michel, C., Perrin, C., Andréassian, V., Anctil, F., and Loumagne, C.: Which potential evapotranspiration input for a lumped rainfall-runoff model? Part 2-Towards a simple and efficient potential evapotranspiration model for rainfallrunoff modelling, J. Hydrol., 303, 290-306, 2005.

Oudin, L., Andréassian, V., Mathevet, T., Perrin, C., and Michel, C.: Dynamic averaging of rainfall-runoff model simulations from complementary model parameterizations, Water Resour. Res., 42, W07410, doi:10.1029/2005WR004636, 2006.

Perrin, C., Michel, C., and Andréassian, V.: Does a large number of parameters enhance model performance? Comparative assessment of common catchment model structures on 429 catchments, J. Hydrol., 242, 275-301, 2001.

Perrin, C., Michel, C., and Andréassian, V.: Improvement of a parsimonious model for streamflow simulation, J. Hydrol., 279, 275289, doi:10.1016/S0022-1694(03)00225-7, 2003.

Poulin, A., Brissette, F., Leconte, R., Arsenault, R., and Malo, J.-S.: Uncertainty of hydrological modelling in climate change impact studies in a Canadian, snow-dominated river basin, J. Hydrol., 409, 626-636, doi:10.1016/j.jhydrol.2011.08.057, 2011.

Prudhomme, C., Jakob, D., and Svensson, C.: Uncertainty and climate change impact on the flood regime of small UK catchments, J. Hydrol., 277, 1-23, 2003.
Quintana Seguí, P., Ribes, A., Martin, E., Habets, F., and Boé, J.: Comparison of three downscaling methods in simulating the impact of climate change on the hydrology of Mediterranean basins, J. Hydrol., 383, 111-124, doi:10.1016/j.jhydrol.2009.09.050, 2010.

Schmidli, J., Frei, C., and Vidale, P.-L.: Downscaling from GCM precipitation: a benchmark for dynamical and statistical downscaling methods, Int. J. Climatol., 26, 679-689, doi:10.1002/joc.1287, 2006.

Scinocca, J. F., McFarlane, N. A., Lazare, M., Li, J., and Plummer, D.: Technical Note: The CCCma third generation AGCM and its extension into the middle atmosphere, Atmos. Chem. Phys., 8, 7055-7074, doi:10.5194/acp-8-7055-2008, 2008.

Seiller, G., Anctil, F., and Perrin, C.: Multimodel evaluation of twenty lumped hydrological models under contrasted climate conditions, Hydrol. Earth Syst. Sci., 16, 1171-1189, doi:10.5194/hess-16-1171-2012, 2012.

Singh, V. P. and Xu, C.-Y.: Evaluation and Generalization of 13 Mass Transfer Equations for Determining Free Water Evaporation, Hydrol. Process., 11, 311-323, 1997.

Sugawara, M.: Automatic calibration of the tank model, Hydrol. Sci. Bull., 24, 375-388, 1979.

Teng, J., Vaze, J., Chiew, F. H. S., Wang, B., and Perraud, J.-M.: Estimating the Relative Uncertainties Sourced from GCMs and Hydrological Models in Modeling Climate Change Impact on Runoff, J. Hydrometeorol., 13, 122-139, doi:10.1175/JHM-D11-058.1, 2012.

Thiery, D.: Utilisation d'un modèle global pour identifier sur un niveau piézométrique des influences multiples dues à diverses activités humaines, IAHS Publ. No. 136, 71-77, 1982.

Thornthwaite, C. W. and Mather, J. R.: The Water Balance, Publications in Climatology, Vol. VIII, No. 1, 1955.

Valéry, A.: Modélisation précipitations - débit sous influence nivale. Élaboration d'un module neige et évaluation sur 380 bassins versants, 417 pp., Agro Paris Tech., 2010.

Velázquez, J. A., Anctil, F., and Perrin, C.: Performance and reliability of multimodel hydrological ensemble simulations based on seventeen lumped models and a thousand catchments, Hydrol. Earth Syst. Sci., 14, 2303-2317, doi:10.5194/hess-14-23032010, 2010.

Velázquez, J.-A., Schmid, J., Ricard, S., Muerth, M. J., Gauvin StDenis, B., Minville, M., Chaumont, D., Caya, D., Ludwig, R., and Turcotte, R.: An ensemble approach to assess hydrological models' contribution to uncertainties in the analysis of climate change impact on water resources, Hydrol. Earth Syst. Sci., 17, 565-578, doi:10.5194/hess-17-565-2013, 2013.

Vicuna, S., Maurer, E. P., Joyce, B., Dracup, J. A., and Purkey, D.: The Sensitivity of California Water Resources to Climate Change Scenarios, J. Am. Water Resour. Assoc., 43, 482-498, doi:10.1111/j.1752-1688.2007.00038.x, 2007.

Wagener, T., Boyle, D. P., Lees, M. J., Wheater, H. S., Gupta, H. V., and Sorooshian, S.: A framework for development and application of hydrological models, Hydrol. Earth Syst. Sci., 5, 13-26, doi:10.5194/hess-5-13-2001, 2001.

Wang, Y. C., Yu, P. S., and Yang, T. C.: Comparison of genetic algorithms and shuffled complex evolution approach for calibrating distributed rainfall-runoff model, Hydrol. Process., 24, 10151026, doi:10.1002/hyp.7543, 2009. 
Warmerdam, P. M. M., Kole, J., and Chormanski, J.: Modelling rainfall-runoff processes in the Hupselse Beek research basin, in Ecohydrological processes in small basins, Proceedings of the Strasbourg Conference (24-26 September 1996), IHP-V, Technical Documents in Hydrology no. 14, 155-160, UNESCO, Paris, 1997.

Wilks, D. S.: Statistical Methods in the Atmospheric Sciences?: An introduction, Academic press, 1995.

Xu, C.-Y. and Singh, V. P.: Dependence of evaporation on meteorological variables at different time-scales and intercomparison of estimation methods, Hydrol. Process., 12, 429-442, 1998.
Xu, C.-Y. and Singh, V. P.: Evaluation and generalization of radiation-based methods for calculating evaporation, Hydrol. Process., 14, 339-349, 2000.

$\mathrm{Xu}$, C.-Y. and Singh, V. P.: Evaluation and generalization of temperature-based methods for calculating evaporation, Hydrol. Process., 15, 305-319, doi:10.1002/hyp.119, 2001.

$\mathrm{Xu}$, C.-Y. and Singh, V. P.: Cross comparison of empirical equations for calculating potential evapotranspiration with data from Switzerland, Water Resour. Manag., 16, 197-219, 2002.

Zhao, R. J., Zuang, Y. L., Fang, L. R., and Zhang, Q. S.: The Xinanjiang model, IAHS Publ. No. 129, 351-356, 1980. 